\title{
User Needs in Smart Homes: Changing Needs According to Life Cycles and the Impact on Designing Smart Home Solutions
}

\author{
Olivia De Ruyck 1,2,3[0000-0002-7786-8612], Peter Conradie ${ }^{1,2}$, [0000-0003-4495-9136] , Jelle Sal- \\ $\operatorname{dien}^{1,2}$ [0000-0003-2557-3764], Lieven De Marez ${ }^{1,3}$ [0000-0001-7716-4079] \\ 1 imec-mict-UGent \\ ${ }^{2}$ Department of Industrial Systems Engineering and Product Design, Ghent University, Kort- \\ rijk, Belgium \\ ${ }^{3}$ Department of Communication Sciences, Ghent University, Ghent, Belgium \\ \{olivia.deruyck, peter. conradie, jelle.saldien, lieven. demarez\} @uge \\ nt.be
}

\begin{abstract}
Smart home solutions are gaining popularity but hold a large untapped potential. This paper presents smart home needs from a user point of view. Based on co-creation workshops with residents of different life cycles in Belgium, it draws conclusions about key issues related to user needs. Starting from these insights we can describe characteristics of inhabitants according to their life cycle. We conclude that their needs for smart solutions and the way they want to equip their homes differ. The younger generation looks for modular systems with possibilities to expand or move them. They are moment oriented and buy Internet of Things (IoT) appliances according to their current needs and budget. The older generation, by contrast, searches for quality and all-inone solutions. They want a complete solution that does not require any updates or extras and is proof for their future needs. The results of this study in the form of eight guidelines can be considered when designing smart home solutions.
\end{abstract}

Keywords: Smart homes; Life cycle; User study; Design guidelines.

\section{Introduction}

In the last decade, popular and scientific attention for smart homes has augmented with consultancy firms like Gartner [16] and Deloitte [10] reporting growing consumer interest. Contrary to the traditional home were appliances respond to commands via fixed buttons and switches, smart homes and smart appliances are controlled from anywhere in the house or over the internet, often through smartphone apps.

Market research in the United States, confirms the increasing interest. Eighty-one percent of US internet users are aware of the concept of smart devices and the connected home after being given a description [38]. Moreover, global consumer research carried out in seven countries worldwide, including the United States and Germany, 
suggests a high level of market support. Half of all respondents believe that smart home solutions will have an impact in their lives in the next few years [17].

However, while consumer interest is increasing, data from Flanders (Belgium) shows that adoption remains limited, as only $8.8 \%$ of respondents report owning either a smart thermostat, lighting or lock. More surprisingly, 27,4\% reported ever hearing of any of these applications [47].

These findings highlight the existing discrepancy between people's needs and the currently available market offerings. Hargreaves and Wilson [21] emphasize this problem by noting that to date, the majority of visions on smart home technologies have not been based on a clear understanding of user-centric benefits. Furthermore, users have not been engaged in a clear, systematic way. The slow adoption rate of smart products, together with the technology push $[18,43]$ instead of a market pull in the market, nurtures the urge to better understand current user needs [35, 53].

Most user studies regarding smart home technology focus on elements that can stimulate adoption of smart home technology. For instance, in the context of the benefits [52] and barriers [1] of existing smart products. Venkatesh [5] developed a model to predict the adoption of a technology in the home. In his MATH model, he states that life cycles are an important predictor. Limited research, however, is to be found on understanding characteristics and needs of home owners and tenants and comparing them over different life cycles.

Current smart home products are not designed with a focus on the user or the life cycle, therefore the goal of this study is to understand different needs per life cycle for smart home products. This leads to the following research objectives:

- to determine characteristics of inhabitants' life cycles

- to determine specific needs and interactions for smart home solutions per life cycle

- to determine possible barriers for adoption according to inhabitants' life cycle

Information gathered from this study should provide managers and designers with a greater understanding of the user needs in the context of the smart home and give them the ability to create new meaningful smart products and interactions.

The remainder of this paper is structured as follows. First, we review prevalent research within the domain of smart home needs. Secondly, we discuss the methods used in this study followed by our results. Finally, we present guidelines for developing smart home solutions taking life cycle into account.

\section{Literature review and background}

Through a review of existing literature, this section will give a short overview of what we mean by the term of smart home, the detected barriers and benefits and who the users of smart homes are. We will briefly describe the existing literature and models on household lifecycles. 


\subsection{What is a Smart Home}

Terms such as 'smart home' [8], 'smart living', 'smart product', 'IoT product' are often conflated. In this paper, we discuss the needs of users in residential homes and thus exclude related smart living environments [44] like smart cities [22] and smart factories [56], which expand the concept beyond the home environment.

Most homes today have appliances and devices like dishwasher, music installation, garage door, heating and lighting. These are operated manually, mostly by pushing a button. Products are not connected, and users need to be present to start interactions. In smart homes, in contrast, it is possible to access them with remote electronic control. In this paper, the term 'smart home' is used as a generic describer for a residence where sensors and appliances can be (remotely) controlled over a network [27]. User interaction happens through buttons, interfaces, gestures, voice or through automatic commands between appliances.

The provided services by smart homes are not restricted to energy management [8] but include all services that correspond to the needs of its inhabitants $[1,7]$.

Smart homes are predicted to remain a hot topic for many years, with an impressive estimated compound annual growth rate (CAGR) of around 24\% between 2016 and 2020 [45]. Nevertheless, not everything that is technologically possible, matches a need on the user side or is economically feasible. It is from this perspective that we believe that by studying the user needs we add a valid contribution to this domain.

\subsection{Barriers and Benefits}

To tap into this large potential of smart homes, several papers have studied the barriers for market adoption of smart homes [1,28, 52]. Cost, privacy, security, reliability, and the interoperability of different technologies are described as current most important obstacles for adoption. A set of sociotechnical concerns with smart home technologies include an increased dependence on technology, electricity networks or outside experts, and the spread of non-essential luxuries inducing laziness in domestic life [1].

Benefits of existing smart home technologies are described by Wilson, Hargreaves and Hauxwell [52]. Following their study, the smart home is dominantly seen through an energy management lens. Over $86 \%$ of UK respondents agreed or strongly agreed that the main purpose of smart home technologies is to control energy, heating and appliances. The study provides a thorough overview of user' perception on smart home technologies through, among others, a national survey and an analysis of marketing material. Other benefits of smart homes are improved security, enhanced leisure, entertainment and extended personal independence for assisted living [7, 39].

\subsection{Research and Users of Smart Homes}

Solaimani et al. [44] noted that research on smart homes is dominated by research on technological developments . Most studies focus on the acceptance of a technology and the user experience by installing smart products, sensors and actuators in the 
homes of the users $[19,30,54,55]$. Other types of studies in this domain are participatory design studies [42] in which people intended to use the system, help to design. Research typically start from a specific idea or target group, the main goal is to develop or improve a product [25]. With our study, on the contrary, we want to take a step back from technology and want first to understand the needs in the homes to, in a later stage, develop products based on these user needs.

Hargreaves and Wilson [20], list types of prospective smart home users: elderly or vulnerable house-holders, rational energy users, technophiles, home improvers and differentiated families. From these groups, elderly or vulnerable house-holders, such as people with disability, visual- and hearing impairments or people with dementia, have most been studied. They have very specific and differentiating characteristics. Smart homes improve their independence, self-determination and freedom of choice [14]. As note by Hargreaves and Wilson [20] elderly in smart homes benefit from safety measurements such as easy access to emergency contacts, fall prevention, or visual and hearing assistance $[2,6,23,29,32]$.

In the domain of energy policy, benefits and risks of smart home technologies [52] have been looked at from different stakeholders' point of view including early adopters versus non-users and industry. In the same domain, Balta-Ozkan [1] found that social barriers such as control, security and cost to smart home diffusion vary by expertise, life-stage and location.

As mentioned in the introduction, in our study we look at the specific context of Belgium where there has traditionally been an emphasis of home ownership [9]. Seventy percent own and build or renovate a house which is slightly above the European average [12]. Belgians tend to buy at their thirties [3].

\subsection{Household Life Cycle}

To conclude our literature study, we looked into studies around household life cycles. Hill \& Rodgers (1964), as cited in Wilkes [51], describe different events impact a life cycle and the relation between different family members like age, having a first child, departure of the last child out of the home, divorce, dissolution of marriage, decease of a spouse and the age of the main earner.

Wells and Gubar [50] describe a traditional model of family life ignoring for example all singles other than young, never married and older. Later studies from Gillis and Enis [34] modernize the life cycle model and base category membership more on age of the woman rather on the age of the man, as her age will be a better predictor for the age of children. They capture the complexity of households by creating a model with 12 stages. Although the model is created in 1982 it already describes newer familial forms as single parents and same sex couples. Previous studies prove the important effect of age and life cycle on the expenditure $[4,13,31]$. We have chosen to use age as the main criterion for categorization of inhabitants' characteristics, but we emphasize that this is not a strict categorization, since persons in the same age groups might have different lifestyles. 


\section{$3 \quad$ Methodology}

To gather information about the user needs and interactions, the qualitative technique of co-design is used [42]. We give preference to this technique, because as noted by Visser et al. [49], generative techniques give access to latent and tacit knowledge, while techniques like observations and interviews are more likely to reveal explicit and observable knowledge. The use of card-based tools during similar workshops are found effective, and characteristics are summarized by Mora [36]. Research projects have found the cards effective in supporting idea generation [46], presenting theoretical constructs and transferring knowledge between theory and practice [11], keeping people at the center of the design process $[26,33]$ and facilitating a shared understanding or steering a discussing when it becomes unproductive [24]. Our intent to use the cards lays more in the ability to encourage conversation than to stimulate idea generation.

A few card tools have specially targeted IoT ideation $[15,36]$. These cards are intended to support IoT design space and to provide triggers for creative reflective ideation of augmented objects. A description of the card deck used follows in the workshop description.

\subsection{Sampling}

Different recruitment strategies were explored in order to attract participants with a high diversity in age and social background. There was a message displayed on a digital wall in the public library, messages were sent through different online channels like Facebook groups and University contact lists, and the project was presented during computer literacy lectures for seniors.

Participants were divided over five focus groups of two hours. The ages of participants ranged between 21 and 71 years because we wanted to focus on people that have purchasing power and possible changing needs. This way we exclude minors with no buying power and dependent elderly who's changing needs are mainly related to health problems as previously mentioned.

The sample consisted of 24 participants, the main criterion to divide our groups was age (age=21-71y; $\mathrm{M}=41,6 ; \mathrm{SD}=16,9)$. Next to this we tried to attain a malefemale balance $(\mathrm{m}=11 ; \mathrm{f}=13)$ and a balance in the type of homes. Eleven participants live in a home which has not been renovated in the last ten years, 13 participants live in (totally) renovated or recently new build home. Prior to the workshops, participants were asked to fill in a questionnaire with socio demographic questions, experience with renovation or building a house. Additionally, we used a limited 10 item version of the Technology Readiness Index (TRI) [37, 48]. The TRI measures the readiness of a respondent to adopt a new technology. This was important for our research as we wanted to focus on the "somewhat resistant" (TRI-10 to -1) and "somewhat technology ready" (TRI 0 to 10) respondents. "Very technology resistant" (TRI -20 to -11) participants were excluded. We measured TRI to prevent our workshop being skewed towards too many highly technology ready or resistant persons.

Finally, participants were compensated with a movie ticket for their time. 


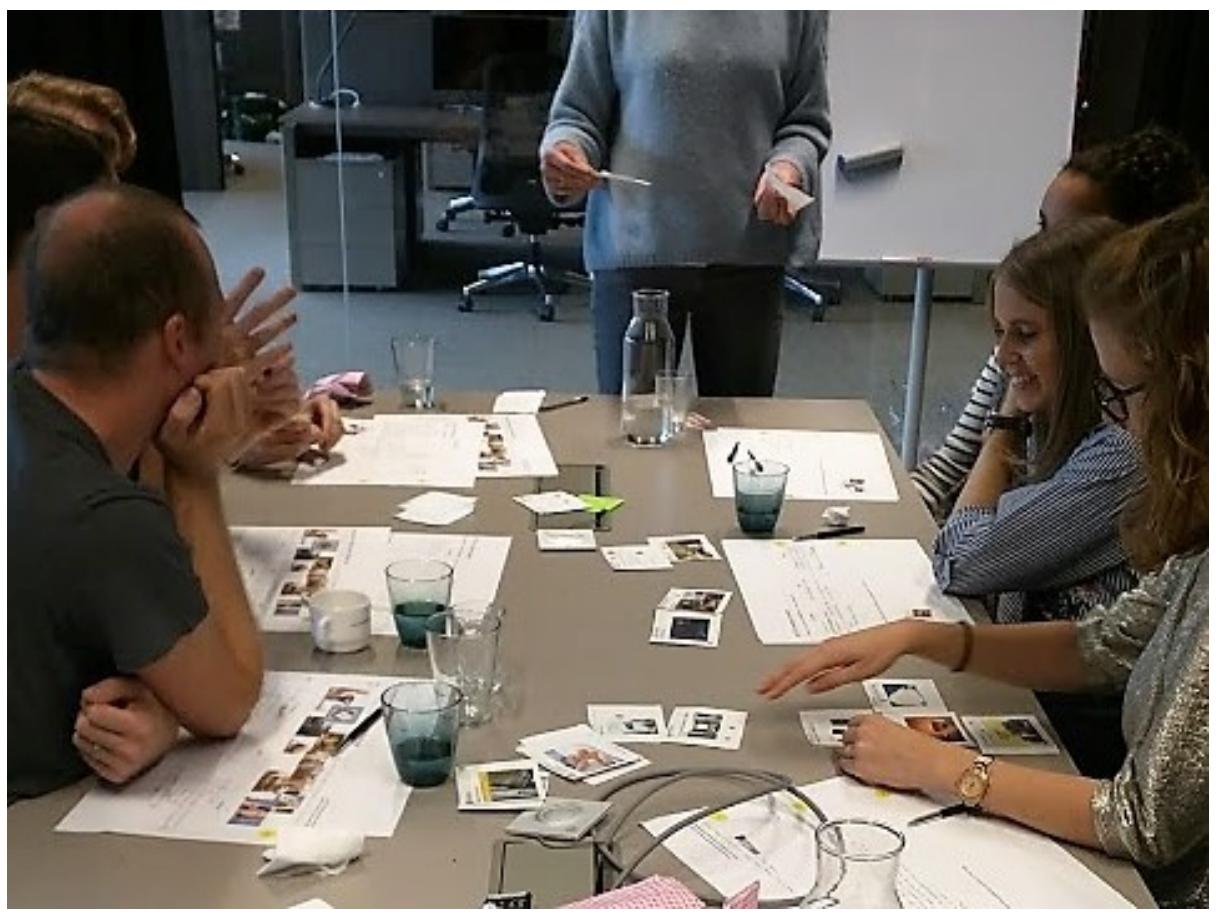

Figure 1. Picture taken during a workshop. Cards encourage workshop participants to discuss their needs and indicate their preferences.

\subsection{Workshop Description}

The workshops were conducted in a creative co-creation space in the Main Library of Ghent at different moments within a four-week period. Consistency between the different groups was ensured by following the same schedule for each session. All sessions were led by 2 researchers, who which facilitated the translation of first ideas around needs in idea sheets. The workshop consisted of short exercises, a discussion moment, a brainstorm to express solutions for their needs and a short presentation of generated ideas by the participants.

To reveal user needs three consecutive exercises were used: first we used a 'day in the life' exercise in which users could describe a week or weekend day. This allowed them to reflect on their activities at home. This was followed by a second exercise in which they had to come up with needs based on these previous mentioned activities. Participants were encouraged to share their needs and frustrations at home out loud. 


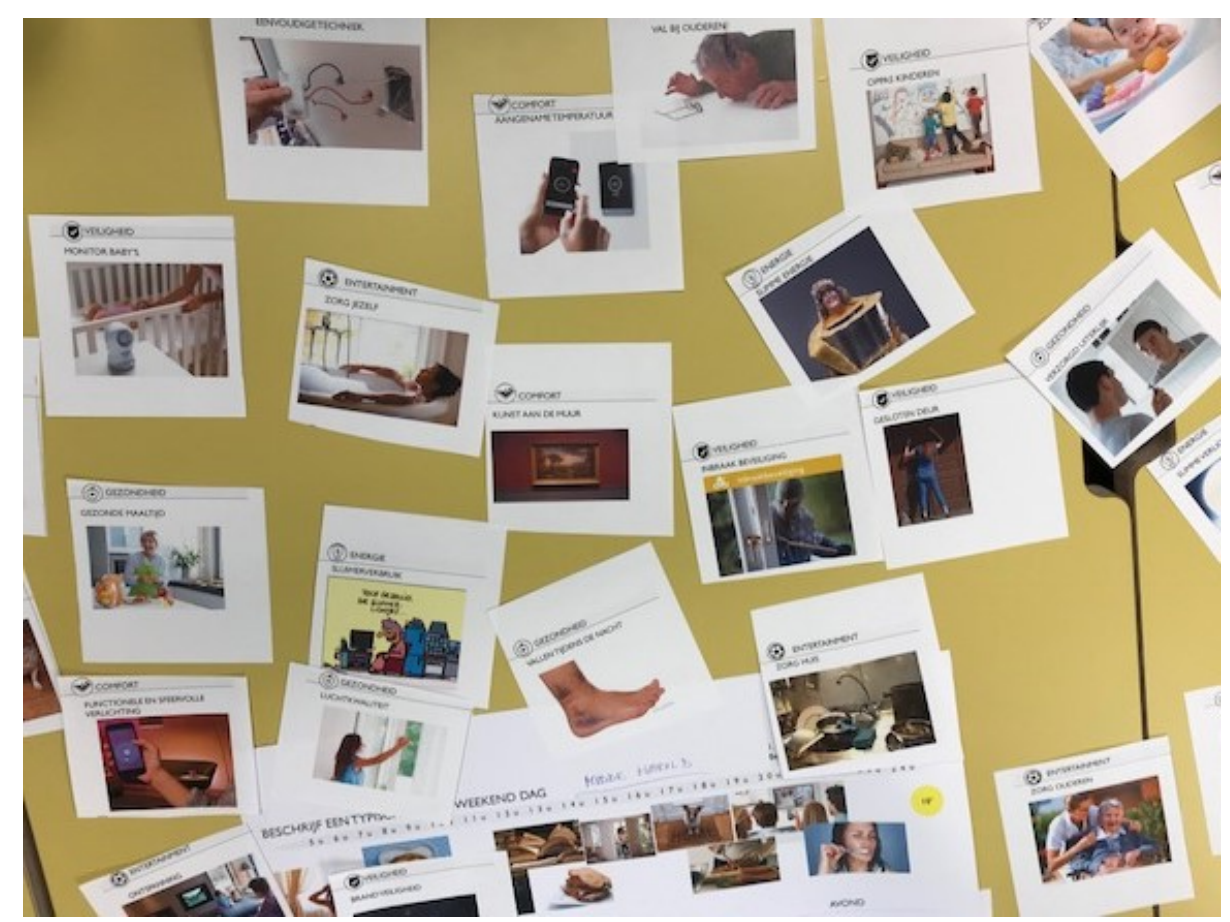

Figure 2. Picture of need cards used during the workshop. Participants can indicate their most important needs with adhesive dots. This enables the researchers to link needs to different life cycles.

To help people pronouncing their needs a third exercise consisted of 30 "need cards" with different categories like safety, comfort, energy use entertainment and health. The cards were custom made for the exercise since no existing card decks could be found which described specific user needs in smart homes.

The need cards are paper cards with a theme, a need and a picture (Figure 2). Examples are protection against burglary; pleasant temperature in the home; control slumber consumption; create a TV moment; good air quality. We iteratively updated the card set during the workshop whenever need sets seemed to be too limited, outdated or duplicated. We encouraged participants to discuss the needs and finally we used the dot selection method to prioritize the needs. Each participant received five stickers with their initials to indicate their top five. The initials allowed the researchers to connect the needs to the socio-demographics of the participants during the analysis of the workshop.

The final part of the workshop consisted of an idea generation based on the most important needs which came out of the dot selection exercise or differently said: the cards with the most votes. Needs could thus vary between the different workshops. The group was now divided in two and both groups needed to come up with a solution for the need they had. If possible, they also needed to describe the way of interaction with the new solution and points of attention like "the door should only close 
automatically when none else is inside the home". As a short intermezzo, barriers towards IoT products in the home were discussed.

As an additional experiment, one of the groups received interaction cards. This is a card kit that describes different ways of interaction. Like the need cards, they are paper cards with a theme, a picture and a description of an interaction like press a button, clap in your hand, talk to something... The kit holds 20 cards which are selected out of existing card sets $[33,36]$ and other existing interactions. The evaluation of the use of these interaction cards is beyond the scope of this paper, but first findings indicate a low influence of the cards on the richness of the generated ideas.

To close the workshop, teams presented on average three ideas to each other. These small presentations push the participants to better prepare and think about solutions and helps researchers to better capture the idea.

\section{$4 \quad$ Findings}

The five workshops -with insights of 24 people aged between 21 and 71 years- resulted in a rich dataset. Over ten hours of video was captured, more than 100 needs were discussed, 31 idea sheets filled in and different discussion themes were cited. The data gathered was consistent across all the sessions. Next, we will present our findings concerning 1. Characteristics of living over life cycles, 2. User needs and interactions according to life cycles and 3. Barriers towards IoT in the home.

Measured TRI levels ranged between 14 and -8 , with an average of 3 (standard deviation of 4.67). Our sample was thus not skewed in favor of too many highly or lowly technologically ready.

\subsection{Characteristics of Living over Life Cycles}

Insights are based on the 'day in the life exercise' in which participants describe their activities, and a discussion during the co-creation workshops.

Results show that people of the same life cycle show similarities in the characteristics of living, needs, and solutions for the home. The presence of children, the size of the home and the ownership impacts the time someone expects to live in a home. This impacts in turn the willingness and the type of investments done in a home.

Life cycles are more easily identified by age. However, this should not be viewed as a rigid categorization. For example, a divorced man in his forties, who moved out of his home to a flat, have more resemblance of living with someone of age group 2535 year than with other men of his age living with a partner and children in a bigger house. A parallel finding was described by Wilkes in his study on household life cycles [51].

The four following names -mentioned from young to old- describe our groups best: Dependent Youngsters, Independent Youngsters, Family Life, Independent Elder. Following we give a description of the common characteristics of these groups, gained from the first workshop exercise. 
Dependent Youngsters. Mainly between 18-25years old. Are characterized for being active and adaptive. This group of people moved -only partially- out of the home. During the week they live in students houses, small apartments or studios. During the weekend, they spend their time at the family home. This new living situation means a reduction of their comfort with smaller and less comfortable rooms. They have little to no impact on the choice of light, heating or energy in their home. They often share spaces with other tenants. While they own few smart home appliances, products like an internet connected sound system are mentioned. "The lights in the corridor of my student house are always on (it is installed this way), I find this so annoying and a wastage." (woman, 22y.)

Independent Youngsters. Mainly between 25-35years old. This group of people moved out from their family home and live alone or with a partner, possibly with small children. They often plan to buy or just bought a property and make purchases to make their home smarter and more efficient (e.g. roof insulation, ventilation, thermostat, smart lamps...). The majority wishes to do this in different phases, often from a cost perspective. They have a preference for appliances which are not built-in and don't come with installation costs, so they can take them along in case they move again to a house which is better adapted to their growing household. "I bought these IKEA lamps which can be controlled by an app. Inexpensive and easy to install in the fittings. If I have more money, I'll buy that smart lock." (man, 30y.) They own a variety of smart home appliances both for augmented control as for entertainment. Products like a smart lock, smart alarm, smart thermostat, air quality sensor, smart lights or internet connected sound system are mentioned.

Family Life. Mainly between 35-55years old. This group lives with their children in a home they bought and refurbished a while ago. They have made large investments in the house in the past. New purchases for the house primarily happen when a product is out of function (e.g.; cooker hood, boiler) or when they hear very positive feedback about a product. "We had mold/fungus on the walls in our house and they needed to install a whole new ventilation system. An expensive case, but now the problem is solved, and we are happy for that." (woman, 50y.) They have a low level of information about smart home products and other novel solutions for the house. They own fewer smart home appliances compared to the independent youngsters. Mentioned appliances are functional, like a smart thermostat and a connected fire alarm.

Independent Elder. Mainly between 55-75years old. They used to live with their children in the home but when they move out, their home often becomes too big. This group of people is searching for new living situations (e.g. co-housing, assistant living, apartment). Construction works to adapt their homes to their new needs (everything on one floor, large doors, smaller home and garden) are often so radical that they opt to move or build again. This makes that they either live in old houses $(>20 \mathrm{y}$.) or in properties with the newest technologies. Contrary to what many would think about this target group, a part of them recently rebuilt and are well informed about 
new building solutions and technology. "I live in a big gentleman's house, since the children moved out, I'm thinking about new ways of living like co-housing or B\&B" (woman, 65y.)

"We bought a land last year and are making the plans with an architect at the moment. In the home everything will be on one floor with large doors in case one of use will need a wheelchair one day. It must be built following latest energy norms with light sensors for convenient living." (man, 67y.)

Participants from this group living in old houses own little to no smart home appliances but own complete wired sound systems, home automation, automated rolling shutters, sensor lights on the driveway. Inhabitants of new houses are more likely to own a smart fire alarm or light sensors in the hallway.

Based on these insights we can propose that Independent Youngsters and Independent Elder are most interesting groups to target; they have high needs in combination with the willingness to invest in new IoT solutions for their homes. However, they want to equip their homes in different ways. The Independent Youngsters search for modular systems with possibilities to expand or move them. They are moment oriented and buy IoT appliances according to their current needs and budget.

The Independent Elder on the other hand, search for quality and all-in-one solutions. They are future oriented and want a complete solution that won't need any updates or extras.

\subsection{User Needs and Interaction According to Life Cycles}

During the co-creation workshops a selection exercise with a set of 30 need cards was used. Participants were asked to write their initials on the dots and stick them on their five highest needs. Priority needs per life stage of our participants are listed in the table below.

Table 1. List with priority needs per life stage based on needs card exercise.

\begin{tabular}{|l|l|l|l|}
\hline $\begin{array}{l}\text { Dependent } \\
\text { youngster } \\
\mathbf{( 1 8 - 2 5 y . )}\end{array}$ & $\begin{array}{l}\text { Independent } \\
\text { youngster } \\
(\mathbf{2 5 - 3 5 y . )}\end{array}$ & $\begin{array}{l}\text { Family } \\
\text { life (35-55y.) }\end{array}$ & $\begin{array}{l}\text { Independent } \\
\text { elder (55-75y) }\end{array}$ \\
\hline $\begin{array}{l}\text { Reminders for } \\
\text { chores in the home }\end{array}$ & $\begin{array}{l}\text { Air quality in the } \\
\text { home }\end{array}$ & $\begin{array}{l}\text { Air quality in the } \\
\text { home }\end{array}$ & Fire prevention \\
\hline $\begin{array}{l}\text { Give others access } \\
\text { to your home }\end{array}$ & $\begin{array}{l}\text { Reminders for } \\
\text { chores in the home }\end{array}$ & $\begin{array}{l}\text { Reminders for } \\
\text { chores in the home }\end{array}$ & Theft prevention \\
\hline $\begin{array}{l}\text { Air quality in the } \\
\text { home }\end{array}$ & $\begin{array}{l}\text { Give others access } \\
\text { to your home }\end{array}$ & Theft prevention & $\begin{array}{l}\text { Temperature } \\
\text { control }\end{array}$ \\
\hline Control lights & Control lights & $\begin{array}{l}\text { Temperature con- } \\
\text { trol }\end{array}$ & $\begin{array}{l}\text { Air quality in the } \\
\text { home }\end{array}$ \\
\hline Manage groceries & $\begin{array}{l}\text { Reduce slumber } \\
\text { consumption }\end{array}$ & Natural light & $\begin{array}{l}\text { Set nice } \\
\text { atmosphere }\end{array}$ \\
\hline
\end{tabular}


By linking the top five needs to the respondents we found differences in needs according to the life cycle. Based on our respondent sample, Youngsters and Elder have most opposite needs.

For young people, products that help them to remind chores in the home and enable remote access to third parties like family members or cleaning personnel score very high. "I would love a fridge with camera and screen that can help you to know what to buy or reminds you to place the garbage outside." (female, 26y.) "I have a smart lock at home. It is great, I can open the door for workmen or the cleaning lady without needing to be there." (man, 31y.)

Older people, in contrast, place security and safety like theft prevention, fire alarms... highest in their ranked needs. Unlike youngsters, they are not fond of the reminders and remote access. "Safety like fire alarms and lights in my garden that switch on to prevent burglary are a priority." (woman, 65y.) "I write paper notes and leave them on the table and my neighbor has my keys. I don't need any product to do this for me" (man, 67y.)

Needs of the Family Life group are less pronounced. A better knowledge of the air quality in and around the home is of common interest between all groups. "Air quality is important for me. I think that my house is healthy, but it is just a guess. I wonder whether it is better or not to open the windows to ventilate the room in the morning when there are traffic jams in my street." (man, 36y.)

Interactions according to life stages. In addition to the difference in functions, also the type of interactions varies between life stages. The Independent Elder understand the advantage of new interactions and are open for them. However, they are more careful. Many would like an additional physical button or switch in case of failure. "My father-in-law has automatic rolling shutters because he couldn't lift the old manual ones anymore. To open them, you still have to push a button so he would keep the feeling of control, and we would know that something is wrong when the shutters are not open in the morning." (woman 54y.)

Dependent and Independent Youngsters are more exposed to new types of interactions (contactless payment, check in through bio data, speech control on the phone) and thus have more confidence. They do not ask for buttons to fall back on. Full automation when interacting with products is accepted. They expect products to be customizable and that settings can be changed.

"I don't mind that products are personalized and automated, it is so easy that my agenda knows me; but the way we interact with products should not disturb others. A smart mat which switches on the lights in the morning when stepping on it, or products with speech control are perfect to me now. They would not be appropriate for families with sleeping children." (man, 29y.) "To enter the gym, I unlock the door with a finger scan (bio data). Great! Fast and easy!” (woman, 22y.)

\subsection{Barriers Towards Acceptance of Smart Home Solutions}

Previous research [53] indicates acceptability of smart homes is closely linked to issues of security, privacy and trust as well as practical and ergonomic concerns with 
user friendliness. During a discussion moment, participants were questioned about barriers towards IoT products. Here again we find some similarities and differences among the life cycles.

Over generations, there is a fear for the effects of Wi-Fi on health. However, rarely this a reason not to accept smart products in the home. This fear was clearly present in all sessions and was not found in previous research on barriers of IoT products[1]. "All this radiance, like while charging an object from a distance and all the smartphones, this can't be healthy, but yes we just buy what is on the market if it is easy." (woman, 65y.) "I don't want Wi-Fi in my home. It can't be healthy to constantly live in that." (woman, 26y.)

Other fears are more outspoken by the Independent Elder. IoT solutions are feared by them for the loss of control and apathy. They think that letting products make their own decisions, will lead to frustration and breakage of the product. "Sensors make me nervous. We had that at work. Sun is there, the screens roll out, sun is gone, screens go up, sun is there again... Terrible!... until it breaks." (man, 71y.)

Another close related fear is the cost and availability of a technician. The fear is that the major cost is not the product itself but the technician in case of problems with the hard- or software.

The last age-related fear is laziness. The Independent Elder fear that all sensors and automation will make them and others lazy and decrease their mobility. Here again this fear is more outspoken with older than younger people. They perceive closing curtains, switching off lights... as physical activities which they want to conduct themselves. However, when they think of themselves or others in case of reduced mobility, they find such kind of solution very useful. Younger respondents don't think these solutions will reduce their physical activity.

"I am here to tell these kids that you need to stand up to switch a light, if not you'll become lazy. But my wife had a hip surgery, I need to do everything for her. In her case, automatic solution are useful." (man, 63y.)

\subsection{Recommendations for designers and managers developing smart home solutions}

From the findings we can draw some conclusions for different types of designers or managers when developing new smart home solutions. They are shortly summarized below.

1. Prior to the development of smart home solutions, the organization of workshops with designated tools help to understand most important needs.

2. User needs for smart home solutions change according to the life cycle. To create a market-pull, a designer should be aware for who he is designing.

3. Needs of Independent and Dependent Youngsters and Independent Elder differ the most. Needs of the Family Life group are less outspoken and have similarities with both other groups.

4. The Independent and Dependent Youngster equip their homes with modular solutions with possibilities to expand the system in the future. Older genera- 
tions are more future oriented and need built-in solutions without any updates required.

5. The Independent Elder can't be neglected when designing smart home solutions since a part of them rebuilds and equips the home with the newest technology.

6. When designing new types of interaction in the home, all groups are open for new interfaces, however, Independent Elder lack confidence and wish for buttons as back up in case of defect.

7. Next to the described barriers for the acceptance of smart home products in previous literature as security, cost, privacy, reliability, interoperability of technologies, dependence on technology, electricity networks or outside experts and laziness. Inhabitants fear the effect of Wi-Fi on health. These barriers should be taken into account in the design or the marketing of the product.

8. Highest ranked needs for smart home solutions of younger people are related to reminding chores in the home and enable remote access to the home to third parties. In contrary, these above-mentioned needs are unwanted by the older target group. Improved safety (fire-, burglary detection) is a priority for them. A better knowledge of the air quality in and around the home is of common interest between all groups.

\section{Discussion \& Conclusion}

This study investigated through workshops the needs of the tenants and home owners in different lifecycles. More specific the research objectives are to determine characteristics of inhabitants' life cycles, specific needs for smart home solutions per life cycle and possible barriers for adoption according to life cycle.

This study is new to our knowledge since it starts from a technology pull: discovering user needs. Were the majority of studies in the smart home have a technology push attitude. Secondly it compares needs for smart home solutions between younger and older inhabitants in the area of Belgium. It can help designers, product managers or software developers of smart products to bring products on the market which take the different life cycle and specific needs into account.

Previous research on barriers to smart home solutions as cost, trust, privacy and loss of control [1] are found in common. An additional unexpected fear for smart home solutions is the effect of Wi-Fi on health. A possible explanation could be that it is described as a fear, rarely as a real barrier not to accept any internet in the home. Another possible reason could be that Belgians are more sensitive about health concerns.

Recommendations should be read bearing in mind the limited number of respondents (24). Sample bias is a possible concern because of the partial recruitment through the library and University website. This may lead to a more educated and socially engaged group. Another potential shortcoming of the study is the fact that participants were questioned out of their home context. The chosen research method of groups 
discussions did not allow for home interviews. This means that the interaction with other products and other inhabitants could not been taken into account and that the focus of the research lays on understanding explicit needs, not implicit needs.

The aim for future research is to translate some of these needs into meaningful interactions. We will amongst others study the design for different rhythms of use (multiple times a day versus some time a year) and how people of different life cycles living together interact with a same product. In this upcoming stage, different mockups will be first tested in a smart home lab setting and later implemented in the homes of the participants.

Acknowledgments. We thank all participants for cooperating in this study. We would also like to thank the reviewers for their feedback on early drafts of this article.

\section{References}

1. Balta-Ozkan, N. et al.: Social barriers to the adoption of smart homes. Energy Policy. 63, 363-374 (2013).

2. Beringer, R. et al.: The "acceptance" of ambient assisted living: Developing an alternate methodology to this limited research lens. Lect. Notes Comput. Sci. (including Subser. Lect. Notes Artif. Intell. Lect. Notes Bioinformatics). 6719 LNCS, 161-167 (2011).

3. Bouyon, S.: Recent trends in EU home ownership. ECRI Comment. 15, 15, 1-8 (2015).

4. Brown, S. et al.: Household technology use: Integrating household life cycle and the model of adoption of technology in households. Inf. Soc. 22, 4, 205218 (2006).

5. Brown, S.A., Venkatesh, V.: Model of Adoption of Technology in Households: A Baseline Model Test and Extension Incorporating Household Life Cycle. MIS Q. 29, 3, 399-426 (2005).

6. Cesta, A. et al.: Monitoring elderly people with the ROBOCARE domestic environment: Interaction synthesis and user evaluation. Comput. Intell. 27, 1, 60-82 (2011).

7. Chan, M. et al.: Smart homes - Current features and future perspectives. Maturitas. 64, 2, 90-97 (2009).

8. Cook, D.J.: How Smart Is Your Home? Science (80-. ). 335, 6076, 15791581 (2012).

9. De Decker, P., Dewilde, C.: Home-ownership and asset-based welfare: the case of Belgium. J. Hous. Built Environ. 25, 2, 243-262 (2010).

10. Deloitte: Switch on to the connected home - The Deloitte Consumer Review. (2017).

11. Deng, Y. et al.: Tango Cards: A Card-based Design Tool for Informing the Design of Tangible Learning Games. Proc. 2014 Conf. Des. Interact. Syst. 695-704 (2014).

12. Eurostat: People in the EU: who are we and how do we live? 2015. (2015). 
13. Fernández-Villaverde, J., Krueger, D.: Consumption over the Life Cycle: Facts from Consumer Expenditure Survey Data. Rev. Econ. Stat. 89, 3, 552565 (2007).

14. Friedewald, M. et al.: Perspectives of ambient intelligence in the home environment q. 22, 221-238 (2005).

15. Futurice: IoT Service Kit, http://iotservicekit.com.

16. Gartner: Leading the IoT: Gartner Insights on How to Lead in a Connected World. (2017).

17. GfK: The truth behind the hype - Insights on consumer attitudes to the smart home. (2016).

18. Haines, V. et al.: Probing user values in the home environment within a technology driven Smart Home project. Pers. Ubiquitous Comput. 11, 5, 349359 (2007).

19. Hargreaves, T. et al.: Keeping energy visible? Exploring how householders interact with feedback from smart energy monitors in the longer term. Energy Policy. 52, November, 126-134 (2013).

20. Hargreaves, T., Wilson, C.: Smart Homes and Their Users. Spinger (2017).

21. Hargreaves, T., Wilson, C.: Who uses smart home technologies? Representations of users by the smart home industry. ECEEE summer study. 1-14 (2013).

22. Harrison, C. et al.: Foundations for Smarter Cities. IBM J. Res. Dev. 54, 4, $1-$ 16 (2010).

23. van Hoof, J. et al.: Ageing-in-place with the use of ambient intelligence technology: Perspectives of older users. Int. J. Med. Inform. 80, 5, 310-331 (2011)

24. Hornecker, E.: Creative idea exploration within the structure of a guiding framework: the card brainstorming game. Proc. fourth Int. Conf. Tangible Embed. embodied Interact. 10, 101-108 (2010).

25. Hwang, A. et al.: Using participatory design to determine the needs of informal caregivers for smart home user interfaces. Proc. 6th Int. Conf. Pervasive Comput. Technol. Healthc. 41-48 (2012).

26. IDEO: IDEO Method Cards: 51 Ways to Inspire Design., Palo Alto (2003).

27. International Telecommunication Union: Measuring the Information Society. , Geneva (2010).

28. Jakobi, T. et al.: The Catch(es) with Smart Home - Experiences of a Living Lab Field Study. Proc. CHI. 1620-1633 (2017).

29. Kim, M.J. et al.: A critical review of user studies on healthy smart homes. Indoor Built Environ. 22, 1, 260-270 (2013).

30. Kim, S., Paulos, E.: InAir: sharing indoor air quality measurements and visualizations. Proc. Conf. Hum. Factors Comput. 1861-1870 (2010).

31. Lawson, R.: Patterns Of Tourist Expenditure And Types Of Vacation Across The Family Life Cycle. J. Travel Res. 29 issue, April 1, 1991, 4, page(s): 1218 (1991).

32. Lorenzen-Huber, L. et al.: Privacy, Technology, and Aging: A Proposed Framework. Ageing Int. 36, 2, 232-252 (2011). 
33. Lucero, A., Arrasvuori, J.: The PLEX Cards and its techniques as sources of inspiration when designing for playfulness. Int. J. Arts Technol. 6, 1, 22 (2013).

34. Mary C. Gilly, B.M.E.: Recycling The Family Life Cycle: A Proposal For Redefinition, http://www.acrwebsite.org/volumes/display.asp?id=6007, (1982).

35. Mennicken, S. et al.: From Today' s Augmented Houses to Tomorrow' s Smart Homes: New Directions for Home Automation Research. 105-115 (2014).

36. Mora, S. et al.: Tiles: A Card-based Ideation Toolkit for the Internet of Things. Proc. 2017 Conf. Des. Interact. Syst. - DIS '17. 587-598 (2017).

37. Parasuraman, A., Colby, C.L.: Techno-ready marketing: How and why your customers adopt technology. The Free Press, New York, NY, USA (2007).

38. PWC: Smart home, seamless life - Unlocking a culture of convenience. PWC Consum. Intell. Ser. January, (2017).

39. Røpke, I., Nyborg, S.: Energy impacts of the smart home - conflicting visions. Eceee 2011 Summer Study. 1849-1860 (2011).

40. Sanders, E.B.-N., Stappers, P.J.: Co-creation and the new landscapes of design. CoDesign. 4, 1, 5-18 (2008).

41. Sanders, E.B.-N., Stappers, P.J.: Probes, toolkits and prototypes: three approaches to making in codesigning, http://dx.doi.org/10.1080/15710882.2014.888183, (2014).

42. Simonsen, J., Robertson, T.: Handbook of Participatory Design. routledge international (2013).

43. Solaimani, S. et al.: The smart home landscape: A qualitative meta-analysis. Lect. Notes Comput. Sci. (including Subser. Lect. Notes Artif. Intell. Lect. Notes Bioinformatics). 6719 LNCS, 192-199 (2011).

44. Solaimani, S. et al.: What we do - and don't - know about the Smart Home: An analysis of the Smart Home literature. Indoor Built Environ. 24, 3, 370383 (2015).

45. Technavio: Global Smart Appliances Market 2016-2020. (2016).

46. Vaajakallio, K., Mattelmäki, T.: Design games in codesign: As a tool, a mindset and a structure, http://dx.doi.org/10.1080/15710882.2014.881886, (2014).

47. Vanhaelewyn, B., De Marez, L.: imec.Digimeter 2017: measuring digital media trends in flanders. (2017).

48. Victorino, L. et al.: Exploring the Use of the Abbreviated Technology Readiness Index for Hotel Customer Segmentation. Cornell Hosp. Q. 50, June, 342-359 (2009).

49. Visser, F.S. et al.: Contextmapping: experiences from practice. CoDesign. 1, 2, 119-149 (2005).

50. Wells, W.D., Gubar, G.: Life Concept in Marketing Research. J. Mark. Res. 3, 4, 355-363 (1966).

51. Wilkes, R.E.: Household Life-Cycle Stages, Transitions, and Product Expenditures. J. Consum. Res. 22, 1, 27 (1995). 
52. Wilson, C. et al.: Benefits and risks of smart home technologies. Energy Policy. 103, September 2016, 72-83 (2017).

53. Wilson, C. et al.: Smart homes and their users: a systematic analysis and key challenges. Pers. Ubiquitous Comput. 19, 2, 463-476 (2015).

54. Woo, J., Lim, Y.: User experience in do-it-yourself-style smart homes. Proc. 2015 ACM Int. Jt. Conf. Pervasive Ubiquitous Comput. - UbiComp '15. 779790 (2015).

55. Yang, R., Newman, M.W.: Learning from a Learning Thermostat: Lessons for Intelligent Systems for the Home. 93-102 (2013).

56. Zuehlke, D.: SmartFactory-Towards a factory-of-things. Annu. Rev. Control. 34, 1, 129-138 (2010). 